\title{
Optimal ratio of spans of continuous bridges
}

\author{
Aleksander Makarov ${ }^{1}$, Sergey Kalinovsky ${ }^{2 *}$, Natalia Ermilova ${ }^{3}$ and Alexey Churakov ${ }^{4}$ \\ ${ }^{1}$ Volgograd State Technical University, Construction and operation of transport facilities \\ Department, 400074 Volgograd, Russian Federation \\ ${ }^{2}$ Volgograd State Technical University, Hydraulic and earth structures Department, 400074 \\ Volgograd, Russian Federation \\ ${ }^{3}$ Volgograd State Technical University, Engineering Graphics, Standardization and Metrology \\ Department, 400074 Volgograd, Russian Federation \\ ${ }^{4}$ Volgograd State Technical University, Building Structures, Foundations and Reliability of \\ Structures Department, 400074 Volgograd, Russian Federation
}

\begin{abstract}
The article deals with the creation of continuous metal and monolithic reinforced concrete bridge spans, which are the most effective. Efficiency is achieved by finding opportunities for the unification of structures with the most successful options for providing them with the required load-bearing capacity with the lowest cost of building materials. The bending moments that occur in the sections of a continuous structure are distributed more evenly and take on smaller values in the span than in a split structure. However, the efficiency of continuous structures can be further improved by introducing a certain coefficient of the length of the extreme spans of the bridge relative to the average ones. This allows you to achieve equality of the reference or span bending moments. As a result, the design will work in such a way that it will be possible to build the bridge span as if from three types of unified blocks, which will reduce the complexity and cost of construction work. As an example, in this case, the ratio of spans and the corresponding division into blocks for four-span continuous bridges are determined.
\end{abstract}

\section{Introduction}

It is known that a continuous static circuit in comparison with a split circuit has a number of advantages. In particular, in a continuous section, smaller bending moments occur and there is a uniform distribution of moments in the spans [1,2]. Thus, the use of continuous structural schemes makes it possible to increase the length of bridge spans. The advantages of a continuous circuit have long been used by designers in practice. However, almost no attention is paid to the search for the most economical ratios of the bridge spans between each other. In the literature, only approximate values of the span ratios are given in general for bridges, and not for specific variants of continuous lashes. Often, the ratio of spans is assigned for reasons of ensuring the architectural expressiveness of the bridge, without checking for its optimality. The issues of choosing the optimal ratios of bridge spans from

\footnotetext{
*Corresponding author: sk0522@yandex.com
} 
the position reflecting the minimization of the operating forces were considered in the works of the authors $[3,4]$ for arch systems.

\section{Research studies, design of bridges}

Continuous bridges can consist of a different number of spans. In bridge construction practice, three-span continuous bridge schemes are often used. An example is the bridge over the Volga-Don Shipping Canal, which is being built on a new bypass road around Volgograd, the need for which was reflected in the work [6] and subsequently emphasized by various news agencies and government representatives [5]. Diagram of the continuous lash of the specified bridge $105+147+105$. The total length of the superstructure is $357 \mathrm{~m}$. For the unification of structures in the design and construction of the size of the average spans should be made the same. The extreme spans must be of such a length that the bending moments in the continuous bridge beam will be the same. In the specialized literature, the data on the variants of such length coefficients are very approximate and not specific $[7,8]$. Accordingly, when using these data, errors are possible, which inevitably lead to the need to prematurely resort to restoring the operational qualities of bridge structures, and, as a result, to additional costs of financial resources [9]. The exact value of the length coefficient of the extreme span of a continuous three-span bridge was determined and described in $[10,11]$. When equating the maximum bending moments in the extreme and middle spans, the following expression is obtained:

$$
\frac{q \cdot l^{2}}{8}-\frac{q \cdot l^{2}\left(n^{3}+1\right)}{4(2 n+3)}=\left(\frac{q \cdot l \cdot n}{2}-\frac{M_{r e f}}{l \cdot n}\right) \cdot\left(\frac{q \cdot l}{2}-\frac{M_{r e f}}{l \cdot n \cdot q}\right)-\frac{q}{2}\left(\frac{l \cdot n}{2}-\frac{M_{r e f}}{l \cdot n \cdot q}\right)^{2},
$$

When solving this equation, the span ratio coefficient is obtained. It is $n=0.794$ if the span moments are equal (the reference moments in a symmetrical three-span bridge are always equal).

Thus, for the equality of the span moments in the beams of the span structure of the bridge over the Volga-Don canal, it was necessary to design a scheme of spans $109+138+109$. Three-span continuous structures are often used when designing overpasses over roads and Railways, at transport interchanges, and in bridges over small rivers.

Calculations of these transport structures for various types of loads can also be performed using well-known calculation systems [12, 13, 14] or using the superelement approach $[15,16]$, which allows optimizing the calculation process.

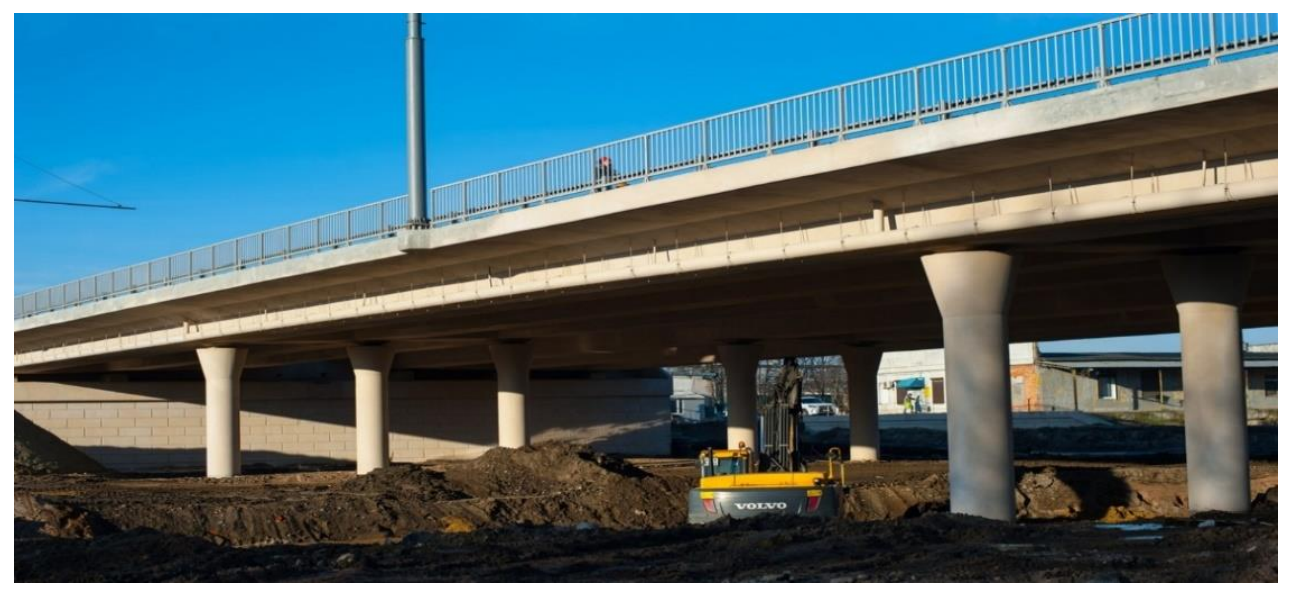

Fig. 1. The bridge is a continuous girder system. 


\section{Determining the optimal span ratio for a four-span bridge and analyzing the results}

Along with three-span continuous bridges, four-span bridges or bridges with four-span continuous lashes are often found. We study the continuous span of the bridge with four spans. Figure 2 shows a diagram of loading a beam with a constant $q_{\text {const }}$ load ( $a$ ), diagrams of bending moments $(b)$ and transverse forces $(c)$.

The studied beam is symmetric, therefore, the system of equations for beam moments consists of two equations [17], because $M_{1}=M_{3}$.

$$
\begin{gathered}
M_{1} \cdot 2 l \cdot(n+1)+M_{2} \cdot l=-6\left(\frac{q_{\text {const }}(n l)^{3}}{24}+\frac{q_{\text {const }} l^{3}}{24}\right) \\
M_{1} \cdot 2 l+M_{2} \cdot 4 l=-6\left(\frac{q l^{3}}{24}+\frac{q_{\text {const }} l^{3}}{24}\right)
\end{gathered}
$$

There are two possible cases in solving this system of equations:

1 - equality of the reference bending moments (Figure 2);

2 - equality of span bending moments (Fig. 3).

Let's consider the first case - equality of reference moments $M_{1}=M_{2}$. Then, according to the second of equations (1), we get $M_{1}=-\frac{q_{\text {const }} l^{2}}{12}$, and according to the first one after the transformations $n^{2}=2 / 3$. The coefficient of the length of the extreme span was $n=$ 0,8165 .

Determine the values of the flying moments. With equal reference moments $M_{1}=M_{2}$, the span moment of the second span will be

$$
M_{2 s}=\left(\frac{q l^{2}}{24}\right)=0,0416 q l^{2} \text {. }
$$

The flying moment of the first flight is obtained from the expression

$$
M_{1 s}=\left(\frac{q l \cdot 0,8165}{2}-\frac{M_{1}}{l \cdot 0,8165}\right) \cdot\left(\frac{l \cdot 0,8165}{2}-\frac{M_{1}}{q l \cdot 0,8165}\right)-q / 2 \cdot\left(\frac{l \cdot 0,8165}{2}-\frac{M_{1}}{q l \cdot 0,8165}\right)^{2} .
$$

Substituting the value of the reference moment $M_{1}$ we get $M_{1 s}=0,0468 q l^{2}$.

The moment values differ by 11 percent.

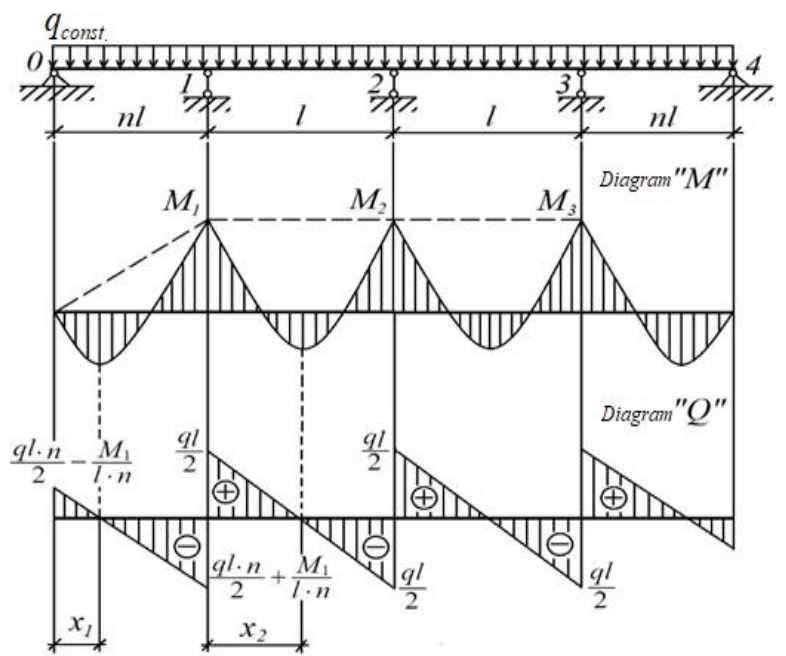

Fig. 2. Scheme of operation of a continuous beam with equal support moments. (Here $x_{1}=\frac{q l \cdot n}{2 q}-$ $\frac{M_{1}}{l \cdot n \cdot q}, x_{2}=\frac{l}{2}$.). 
In the second case, a new equation is required to meet the condition of equality of span moments in a continuous beam. Figure 3 shows the span sections where the maximum bending moments will be applied. In this case, the reference moments are not equal.

$$
\begin{gathered}
M_{1 \text { ref }}=\left(\frac{q \cdot l \cdot n}{2}-\frac{M_{1}}{l \cdot n}\right) \cdot\left(\frac{l \cdot n}{2}-\frac{M_{1}}{q \cdot l \cdot n}\right)-q / 2 \cdot\left(\frac{l \cdot n}{2}-\frac{M_{1}}{q \cdot l \cdot n}\right)^{2} \\
M_{2 r e f}=\left(\frac{q \cdot l \cdot n}{2}-\frac{M_{1}}{l \cdot n}\right) \cdot\left(l \cdot n+\frac{M_{1}-M_{2}}{q l}+l / 2\right)-\left(\frac{q \cdot l \cdot n}{2}+\frac{M_{1}}{l \cdot n}+\frac{q \cdot l}{2}+\frac{M_{1}-M_{2}}{l}\right) \cdot\left(\frac{M_{1}-M_{2}}{q \cdot l}+\frac{l}{2}\right)+ \\
+q / 2\left(l \cdot n+\frac{M_{1}-M_{2}}{q \cdot l}+\frac{l}{2}\right)^{2}
\end{gathered}
$$

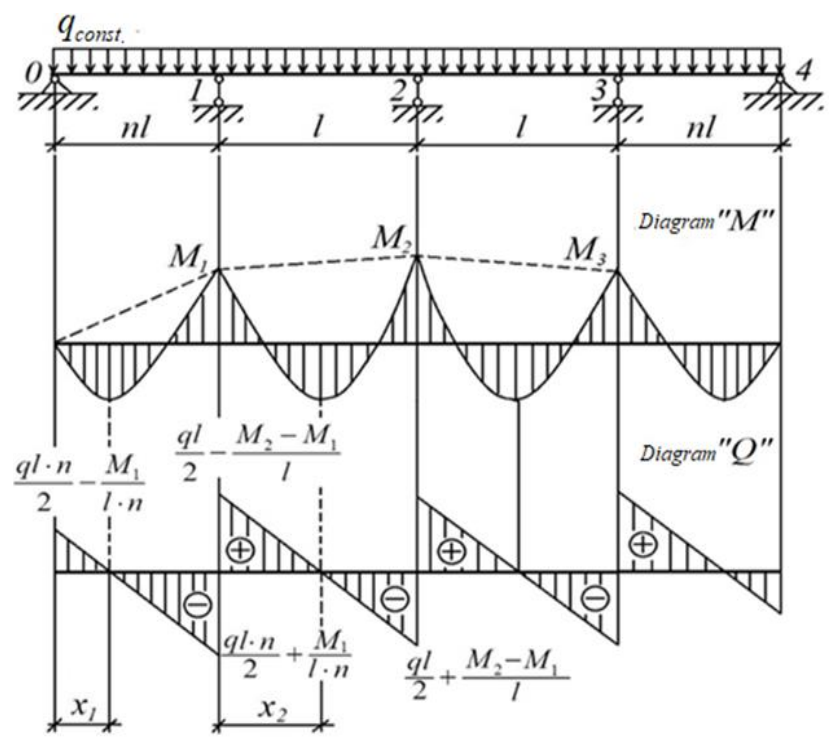

Fig. 3. Scheme of operation of a continuous beam with equal span moments. (Here $x_{1}=\frac{q l \cdot n}{2 q}-\frac{M_{1}}{l \cdot n \cdot q}$, $x_{2}=\frac{l}{2}-\frac{M_{2}-M_{1}}{l q}$.).

Expressing the values of the moments from the system (1) and substituting in the expression (2) and (3) after the transformations, we get the resolving equation in the form

$$
\begin{aligned}
& \left(\frac{n}{2}-\frac{1}{4 n} \cdot\left(1+\frac{4 n+2-2 n^{3}}{-4 n-3}\right) \cdot\left(\frac{n}{2}-\frac{1}{4 n} \cdot\left(1+\frac{4 n+2-2 n^{3}}{-4 n-3}\right)\right)-\frac{1}{2} \cdot\left(\frac{n}{2}-\frac{1}{4 n} \cdot\left(1+\frac{4 n+2-2 n^{3}}{-4 n-3}\right)\right)^{2}-\right. \\
& \left(\frac{n}{2}-\frac{1}{4 n} \cdot\left(1+\frac{4 n+2-2 n^{3}}{-4 n-3}\right)\right) \cdot\left(n+\frac{1}{2}-\frac{1}{2} \cdot\left(\frac{n+\frac{1}{2}-0,5 n^{3}}{-4 n-3}\right)+\frac{1}{4} \cdot\left(1+\frac{4 n+2-2 n^{3}}{-4 n-3}\right)\right)-\left(\frac{n}{2}+\frac{1}{4} \cdot\right. \\
& \left.\left(1+\frac{4 n+2-2 n^{3}}{-4 n-3}\right)+\frac{1}{2} \cdot\left(\frac{n+\frac{1}{2}-0,5 n^{3}}{-4 n-3}\right)+\frac{1}{4} \cdot\left(1+\frac{4 n+2-2 n^{3}}{-4 n-3}\right)+\frac{1}{2}\right) \cdot\left(-\frac{1}{2} \cdot\left(\frac{n+\frac{1}{2}-0,5 n^{3}}{-4 n-3}\right)+\frac{1}{4} .\right. \\
& \left.\left(1+\frac{4 n+2-2 n^{3}}{-4 n-3}\right)+\frac{l}{2}\right)+\frac{1}{2}\left(n-\frac{1}{2} \cdot\left(\frac{n+\frac{1}{2}-0,5 n^{3}}{-4 n-3}\right)+\frac{1}{4} \cdot\left(1+\frac{4 n+2-2 n^{3}}{-4 n-3}\right)+\frac{1}{2}\right)^{2}=0
\end{aligned}
$$

Solving the equation with respect to $n$ we get the coefficient of the length of the extreme span $n=0,787$.

The reference moments are determined from the solution of the system of equations (1) and for $n=0,787$ they are: $M_{1}=-\frac{q_{\text {const }} l^{2}}{14}, M_{2}=-\frac{6 q_{\text {const }} l^{2}}{56}$.

The values of the reference moments acting in a continuous beam differ by 5 percent. 
The equality of support or span bending moments in the sections of the superstructure allows you to divide the entire continuous superstructure into unified blocks of three characteristic types:

- first block $(B 1)$ - calculated on the current span positive moments;

- the second block (B2) accepts loads in the area of internal, intermediate supports;

- the third block (B3) is intermediate, combining the two previous blocks, and perceiving small moments of both signs or the end block.

We show a split into unified blocks of a span structure with Central spans of 63 meters. The extreme spans, taking into account the obtained coefficients, will be 52,5 meters if the span moments are equal. Total length of the bridge of the received scheme $52,5+63+63+$ 52,5 it will be 231 meters, which corresponds to 11 blocks of 21 meters each. Standard block lengths of 21 meters and 10,5 meters are used in the design and construction of metal bridges. By placing the blocks in accordance with the current forces, we get an economical bridge span (Figure 4).

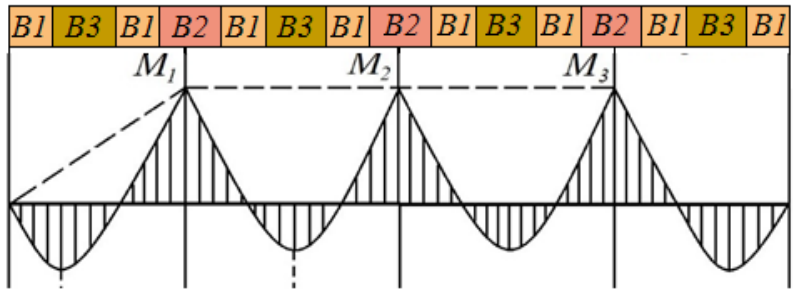

Fig. 4. Scheme for dividing the continuous lash of the bridge superstructure into unified blocks: $B 1-$ span section block, $B 2$ - support section block, $B 3$ - intermediate block.

In modern conditions, BIM-technologies are increasingly used in the design of road infrastructure and artificial structures $[18,19]$. Standardization and unification at the same time again become a requirement of the time, which is reflected in the ODM 218.1.0022010 (Recommendations for the organization and conduct of standardization work in the road sector. The Agency, Moscow, 2010). Models of unified spans of bridge structures can be included in data models when designing road infrastructure [20].

\section{Conclusions}

Based on the above, we can draw the following conclusions:

1. In continuous beam superstructures, it is possible to assign the dimensions of spans so that the effective reference moments take the same values.

2. Equality of the values of the effective reference moments requires a ratio of spans $1 / 0,787$, and equality of the span moments $-1 / 0,8165$.

3. The action of the same bending moments (support or span) in the beams of the bridge superstructure allows the use of unified blocks in the design and construction, which reduces costs.

\section{References}

1. P.M. Salamakhin, Engineering structures in transport construction (Academy Publishing House, Moscow, 2008) 352 p.

2. V.V. Biryulev, Metal continuous structures with adjustment of the support level (Stroyizdat, Moscow, 1984) 88 p. 
3. A.V. Makarov, S. A. Kalinovsky, A. V. Sinitsyn, Optimization of the shape of arch bridge spans, Bulletin of Volgograd State University of Architecture and Civil Engineering. Series: Civil Engineering and Architecture 52(71) (2018) pp. 117 - 127

4. A.V. Makarov, S.A. Kalinovsky, Methods of regulating thrust in design of arch bridges, IOP Conference Series: Materials Science and Engineering, 451(1) 012054 (2018) 7p. URL: https://iopscience.iop.org/article/10.1088/1757899X/451/1/012054/pdf. DOI: 10.1088/1757-899X/451/1/012054

5. Volgograd V1 Access https://v1.ru/text/transport/66347614 / Accessed 7.04.2020 (2020)

6. D.S. Perchenko, A.V. Makarov, Solution of the transport situation of the Krasnoarmeysky district of Volgograd by putting a new bridge into operation, Youth and scientific-and-technical progress in the road industry of the South of Russia: materials of the XI International Scientific-technical Journal. Conference of Students, Postgraduates and Young scientists, May 24-26, 2017 (Volgograd,VSTU, Volgograd, 2017) pp. 60-63

7. M.M. Korneev, Steel bridges: A theoretical and practical guide to design (Mostbet, Kiev, 2003) 547 p.

8. P.M. Salamakhin, Design of bridges and building structures (KNORUS, Moscow, 2013) $402 \mathrm{p}$.

9. S.S. Rekunov, On the assessment of reliability and restoration of operational qualities of bridge structures, Transport structures Vol. 3 no.2 (2016) 7 p. URL: http://ts.today/PDF/07TS216.pdf.

10. A.V. Makarov, S.A.Kalinovsky, Design features of bimetallic bridges, in Proceedings of the XXII International Scientific Conference «Construction the Formation of Living Environment» (FORM-2019). E3S Web of Conferences 97, 06001 (2019) 9p. https://doi.org/10.1051/e3sconf/20199706001

11. A.V. Makarov, A.E. Kupreschenkov, On the issue of designing bimetallic bridges, Engineering Bulletin of the Don 2 (2018) 12 p. URL: http://www.ivdon.ru/ru/magazine/archive/N2y2018/4961

12. V.A. Ignatiev, A.V. Makarov, Solution of the incomplete algebraic problem of eigenvectors and eigenvalues for dynamics and stability problems by the method of frequency-dynamic condensation, Construction mechanics and calculation of structures 1 (2005) pp. 14-20

13. V.A. Ignatiev, V.V. Galishnikova, Application of the frequency-dynamic condensation method for solving the complete algebraic problem of eigenvectors and eigenvalues, Bulletin of the Volgograd State University of Architecture and Civil Engineering. Series: Natural Sciences 3(10) (2004) pp. 3-6

14. V.A. Pshenichkina, G.V. Voronkova, S.S. Rekunov, Research of the dynamical system «beam - stochastic base», Procedia Engineering Vol. 150 (2016) pp. 1721-1728

15. A.V. Makarov, K.A. Sukhin, and I.G. Dovzhenko, Determination of the natural vibration frequencies of systems using a superelement variant of frequency-dynamic condensation, Construction materials 11 (2004) pp. 50-51

16. V.A. Ignatiev, A.V. Makarov, Superelement variant of the frequency-dynamic condensation method, Spatial structures of buildings and constructions (Belglass, Belgorod, 1996) pp. 19-25

17. A.V. Darkov, V. A. Shaposhnikov, Construction mechanics: textbook (12th ed) (Lan Publishing House, Saint Petersburg, 2010) 656 p. 
18. A.I. Savenko, P.V. Cherenkov, General data environment in the implementation of construction projects using BIM, Systems of automated designing and GIS of highways 2(13) 2019 («Giprostroymost Institute», Tomsk, 2019) pp. 4 - 11

19. I. V. Snezhko, D. A. Petrenko, BIM-indorcad tools for project development at a new level, Systems of automated designing and GIS of highways 2(13) 2019 («Giprostroymost Institute», Tomsk, 2019) pp. $32-37$

20. A.V. Skvortsov, BIM Data Models for Infrastructure, Systems of automated designing and GIS of highways 1(4) 2014 («Giprostroymost Institute», Tomsk, 2014) pp. 16-23 